\title{
Emulsion Copolymerization of Polyangelicalactone with Styrene
}

\author{
Konstantin L. Kaygorodov ${ }^{a}$, Valery E. Tarabanko*a, \\ Marina A. Smirnova ${ }^{a}$, Nikolay Tarabanko ${ }^{a}$, \\ Yuri N. Malyar and Vasiliy D. Voronchikhin ${ }^{\mathrm{b}}$ \\ anstitute of Chemistry and Chemical Technology SB RAS \\ FRC "Krasnoyarsk Science Center SB RAS" \\ 50/24 Akademgorodok, Krasnoyarsk, 660036, Russia \\ ${ }^{b}$ Reshetnev Siberian State University of Science and Technology \\ 82 Mira, Krasnoyarsk, 660049, Russia
}

Received 23.01.2019, received in revised form 29.01.2019, accepted 20.04.2019

For the first time emulsion polymerization of polyangelicalactone with styrene was carried out. Block copolymers with a molecular weight of 40000-1000000 and containing 5-40 wt. \% of styrene were prepared. Polymerization rate constants were evaluated. Mechanical properties were evaluated after the copolymers were cured. The cured block copolymers satisfy the basic requirements for high impact polystyrene, and they are biodegradable.

Keywords: alfa-angelicalactone, 5-methyl-2(3H)furanone, cellulose, polyangelicalactone, polyfuranone, styrene, copolymers.

Citation: Kaygorodov K.L., Tarabanko V.E., Smirnova M.A., Tarabanko N., Malyar Yu.N., Voronchikhin V.D. Emulsion copolymerization of polyangelicalactone with styrene, J. Sib. Fed. Univ. Chem., 2019, 12(2), 261-268. DOI: 10.17516/19982836-0124.

(c) Siberian Federal University. All rights reserved

* Corresponding author E-mail address: veta@icct.ru 


\section{Эмульсионная сополимеризация}

\section{полиангеликалактона и стирола}

К.Л. Кайгородов ${ }^{\text {a }}$ В.Е. Тарабанько М.А. Смирнова ${ }^{a}$, Н.В. Тарабанько Ю.Н. Маляр ${ }^{a}$, В.Д. Ворончихин ${ }^{6}$ ${ }^{a}$ Институт химии и химической технологии СО РАН ФИЦ «Красноярский научный центр СО РАН» Россия, 660036, Красноярск, Академгородок, 50/24 ${ }^{6}$ Сибирский государственный университет науки и технологий им. ак. М.Ф. Решетнева Россия, 660049, Красноярск, пр. Мира, 82

Впервые проведена эмульсионная сополимеризация полиангеликалактона и стирола. Получены блок-сополимеры с содержанием стирола 5-40 мас. \% и молекулярной массой от сорока тысяч до миллиона. Оценены константы скорости полимеризации. Изучены механические свойства отвержденных сополимеров. Отвержденные блок-сополимеры удовлетворяют основным требованиям к ударопрочному полистиролу и поддаются биодеградации.

Ключевые слова: альфа-ангеликалактон, 5-метил-2(3Н)-фуранон, целлюлоза, полиангеликалактон, полифуранон, стирол, сополимеры.

Альфа-ангеликалактон (5-метил-2(3Н)-фуранона) - перспективное фурановое производное, лактон левулиновой кислоты; последнюю получают гидролизом целлюлозы и других гексозных углеводов. Полиангеликалактон (ПАЛ) - непредельный полиэфир, получаемый анионной полимеризацией (1) $\alpha$-ангеликалактона $[1,2]$. Полимеризация (рис. 1) протекает в присутствии гидроксида и бутилата натрия [1, 3], октаноата олова [2].

ПАЛ с молекулярной массой до 20000 легко подвергается биодеградации в почве до статистически нетоксичных продуктов $[1,3]$. Поэтому олигомеры ПАЛ можно рассматривать в качестве основы для создания биодеградируемых блок-сополимеров промышленных полимеров. Полиангеликалактон, на стадии анионной полимеризации модифицированный добавками стирола 1-5 \%, имеет молекулярную массу порядка $200000 \div 500000$ и физико-механические свойства, превосходящие требования к стиролу общего назначения. Такой сополимер поддает-<smiles>CC1=CCC(=O)O1</smiles>

Рис. 1. Схема полимеризации $\alpha$-ангеликалактона

Fig. 1. Scheme of $\alpha$-angelicalactone polymerization 
ся биодеградации в серой лесной почве [4]. $\alpha$-Ангеликалактон и полиангеликалактон способны сополимеризоваться со стиролом, капролактамом, этилентерефталатом и метилметакрилатом в условиях анионной полимеризации $[5,6]$.

Возможности радикальной сополимеризации стирола и полиангеликалактона в литературе не рассматриваются. Цель данной работы заключается в получении блок-сополимеров ПАЛ и стирола методом самоэмульгирующейся радикальной сополимеризации при инициировании 4,4`-азобис-4-цианпентановой кислотой и в изучении свойств отвержденных сополимеров.

\section{Экспериментальная часть}

$\alpha$-Ангеликалактон (Alfa Aesar, 98 \%) перед использованием очищали дробной кристаллизацией из расплава. Стирол, стабилизированный гидрохиноном (АО «Химреактивснаб», «ч», $1 \%$ гидрохинона), перед использованием последовательно промывали однократно водным раствором $\mathrm{NaOH}$ (5 масс. \%) и четырехкратно водой, сушили над безводным сульфатом натрия, после чего подвергали фракционной вакуумной перегонке.

4,4'-Азобис-4-цианпентановую кислоту получали согласно методике [7], триизопропилат алюминия - методике [8]. Тетрагидрофуран (АО «Химреактивснаб», «ч») перед использованием промывали насыщенным водным раствором $\mathrm{NaOH}$, подвергали перегонке под вакуумом и далее очищали длительным кипячением с обратным холодильником в присутствии металлического натрия с добавлением бензофенона $(0,2-0,3$ масс. \%) в токе очищенного аргона.

Полиангеликалактон получали анионной полимеризацией в растворе в тетрагидрофуране (инициатор - триизопропилат алюминия). В колбу емкостью 0,25 л с обратным холодильником помещали 100 мл тщательно осушенного тетрагидрофурана, 0,06 г бензофенона, 0,01 г натрия металлического (мелкие чешуйки). После образования кетила в колбу в токе аргона загружали 0,6 г триизопропилата алюминия. Далее в систему загружали 10 г $\alpha$-ангеликалактона. При температуре кипения тетрагидрофурана продолжительность полимеризации 60 мин. Из полученных смол выделяли первую представительную фракцию методом дробного переосаждения этанолом из тетрагидрофурана. Средневесовая молекулярная масса полученного образца полиангеликалактона составила $12000 \pm 2000$.

Самоэмульгирующаяся сополимеризация ПАЛ и стирола. При перемешивании к 90 мЛ воды в колбе на 200 мл добавляли суспензию ПАЛ в 0,4 N водном растворе $\mathrm{NaOH}$ при Т = $343 \mathrm{~K}$. Затем температуру снижали до 303 К. Через 15 мин добавляли стирол и перемешивали в течение 3 ч для растворения ПАЛ.

Затем в реакционную смесь добавляли 0,1 г 4,4`-азобис-4-цианпентановой кислоты, растворенной в небольшом количестве ацетона. Сополимеризацию запускали быстрым нагревом смеси до рабочей температуры реакции $340 \pm 3$ К. Сополимеризацию прерывали, охлаждая колбу в ледяной ванне и добавляя 100 мг гидрохинона. Полученные сополимеры осаждали с помощью 5 мл $2 \mathrm{~N} \mathrm{HCl}$, отфильтровывали и промывали 1,5 л воды до нейтральной реакции.

Изменение концентрации стирола в процессе полимеризации определяли с помощью метода газожидкостной хроматографии толуольных экстрактов из проб реакционной массы.

Величины характеристических вязкостей и молекулярных масс определяли на капиллярных вискозиметрах (диаметры капилляров 0,12 и 0,56 мм) в 98\%-й муравьиной кислоте при $\mathrm{T}=293 \mathrm{~K}$. 
Отверждение полученных сополимеров. Для отверждения полученных сополимеров ПАЛ-стирол к подготовленным образцам добавляли эфират трифторида бора в количестве $5 \times 10^{-3} \%$ от массы образца микрогеля. Затем полученную массу помещали в разогретую до температуры $423 \pm 10 \mathrm{~K}$ пресс-форму и прессовали под давлением 2 МПа. После охлаждения форм образцы извлекали и исследовали.

Физико-механические характеристики (разрушающее напряжение $\sigma_{\mathrm{p}}$, предел текучести $\sigma_{\mathrm{t}}$, относительное удлинение $\varepsilon$ ) определяли в соответствии с ГОСТ 11262-80 при температуре испытания $20 \pm 2{ }^{\circ} \mathrm{C}$. Исследуемые образцы вырубали из пластин, полученных методом прямого горячего прессования в соответствии с ГОСТ 12019-66. Изучали образцы, поверхность которых была гладкой, без вздутий, трещин и прочих дефектов. Толщина образцов для определения физико-механических свойств составляла $0,1 \pm 0,01$ см. Образцы испытывали на лабораторной установке, откалиброванной по результатам определений на машине ZMGI 250, не менее чем через 24 ч после их изготовления и предварительно кондиционировали при температуре испытания в течение 4 ч.

Оценка способности к биодеградации. Из полученных при отверждающем прессовании пластин вырубали образцы размером 0,5 × 0,5 × 0,1 см. Для оценки почвенной биодеградации образцы помещали в почву соснового бора с травянистым покровом на глубину $2-4$ см в весенний период. Для оценки биодеградации в компосте образцы помещали в сетчатые футляры из нержавеющей стали и с помощью зонда погружали на глубину 40 - 50 см в активную компостную кучу из растительных остатков объемом от 1,2 до $1,5 \mathrm{~m}^{3}$. Компостную кучу периодически увлажняли водой с биопрепаратом Bacillus subtilis (штамм 26Д) ( $5 \times 10^{7}$ КОЕ/л). По истечении времени экспозиции образцы извлекали, тщательно промывали, высушивали и измеряли потерю их массы.

\section{Результаты и их обсуждение}

Кинетика процесса. Путем самоэмульгирующейся сополимеризации были получены блок-сополимеры ПАЛ и стирола (рис. 2).

В табл. 1 представлены составы исследованных композиций, а на рис. 3 - данные по кинетике расходования стирола в процессе сополимеризации эмульсий ПАЛ-стирол в полулогарифмических координатах.
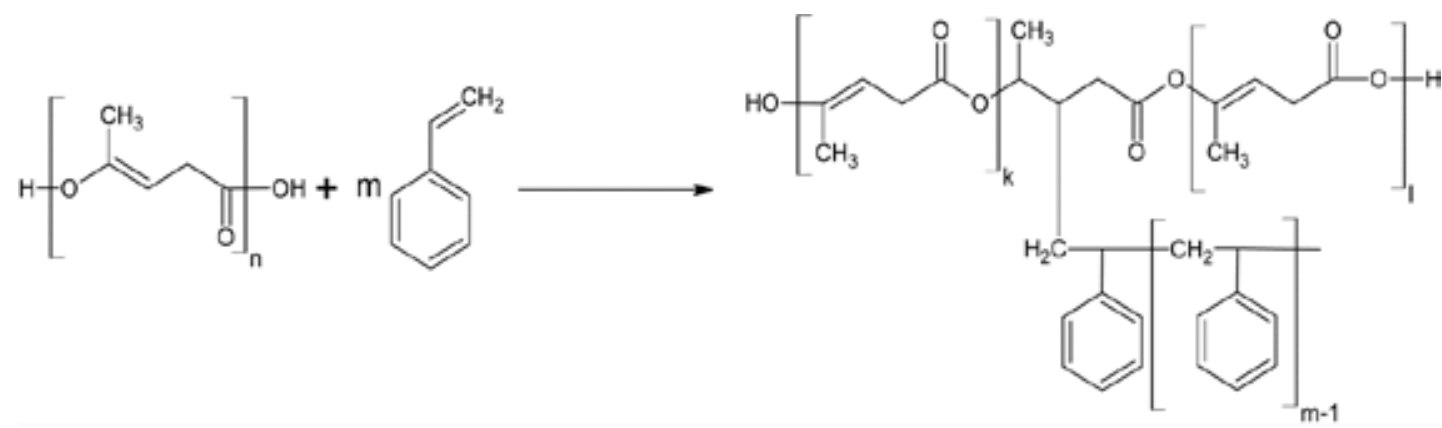

Рис. 2. Схема сополимеризации ПАЛ и стирола

Fig. 2. Scheme of polyangelicalactone - styrene copolymerization 
Таблица 1. Составы эмульсий (90 мл воды) при получении сополимеров ПАЛ-полистирол

Table 1. The emulsion contents (include $90 \mathrm{ml}$ of water) for production of polyangelicalactone - polystyrene copolymers

\begin{tabular}{|c|c|c|c|c|c|}
\hline \multirow{2}{*}{$№$} & \multicolumn{2}{|c|}{ Мольная доля мономеров, \% } & \multirow{2}{*}{ m(ПАЛ), г } & m(стирол), г & \multirow{2}{*}{$\mathrm{NaOH}(0.4$ н), мЛ } \\
\cline { 2 - 3 } & Стирол & ПАЛ & & 0,25 & 12 \\
\hline 1 & 4,72 & 95,28 & 4,75 & 0,5 & 11 \\
\hline 2 & 9,47 & 90,53 & 4,5 & 1 & 9 \\
\hline 3 & 19,06 & 80,94 & 4 & 1,5 & 8 \\
\hline 4 & 28,76 & 71,24 & 3,5 & 2 & 7 \\
\hline 5 & 38,57 & 61,43 & 3 & & \\
\hline
\end{tabular}

Полученные зависимости при заданных концентрациях ПАЛ линейны, и, следовательно, процесс полимеризации можно описать кинетическим уравнением первого порядка по концентрации стирола. Значения наблюдаемых констант скорости первого порядка возрастают пропорционально увеличению начальной концентрации стирола в пределах точности эксперимента (рис. 3). Такое поведение системы может быть описано простейшим кинетическим уравнением (1):

$$
\mathrm{W}=\mathrm{k}_{\mathrm{p}}[\mathrm{R} \cdot][\mathrm{St}],
$$

где $\mathrm{k}_{\mathrm{p}}$ - константа скорости продолжения цепи; [R·] - стационарная концентрация радикала, на котором растет цепь; [St] - текущая концентрация мономера (стирола) в системе. Это уравнение описывает результаты, представленные на рис. 3 и 4 в предположениях: (а) пропорциональности стационарной [R·] начальной концентрации стирола и (б) постоянства стационарной концентрации растущего радикала цепи во времени:

$$
[\mathrm{R} \cdot]=\operatorname{const}(\mathrm{t}) *[\mathrm{St}]_{0} \text {. }
$$

Полученные результаты (рис. 3,4$)$ и их описание (уравнения (1), (2)) указывают на то, что развитие цепи протекает в основном путем взаимодействия активного центра с молекулами стирола, а скорость взаимодействия R· с молекулами ПАЛ относительно мала.

Свойства блок-сополимера полиангеликалактон-стирол. Молекулярная масса сополимеров возрастает в процессе полимеризации с 6-9 тыс. до 40-1200 тыс. и возрастает при увеличении доли стирола в сополимере (рис. 5). Молекулярная масса ПАЛ в начальный момент полимеризации в полтора-два раза меньше по сравнению с показателем синтезированного полимера. Вероятно, такое падение обусловлено щелочным гидролизом полиэфира в процессе приготовления эмульсии.

Физико-механические характеристики отвержденных микрогелей представлены в табл. 2, и они показывают, что полученные материалы по прочностным показателям превосходят требования ГОСТ 28250-89 к ударопрочному полистиролу.

Биодеградация блок-сополимеров. При выдерживании полученных сополимеров в почве и компосте в течение 20 недель масса образцов полученных отвержденных сополимеров уменьшается (табл. 3). При этом наблюдалось помутнение, истончение, растрескивание и при

$$
-265-
$$




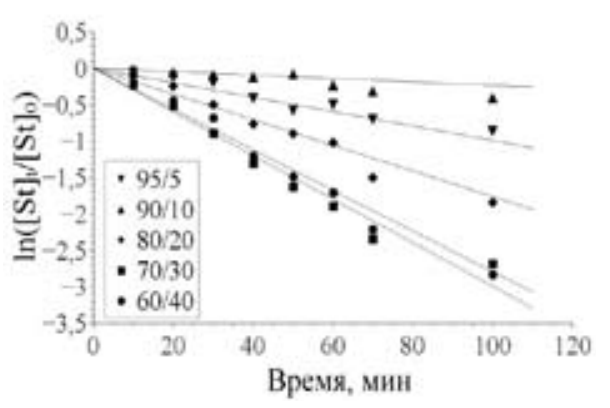

Рис. 3. Кинетика сополимеризации эмульсий ПАЛ-стирол в координатах зависимости первого порядка по концентрации стирола

Fig. 3. Copolymerization kinetics of polyangelicalactone-styrene emulsions in coordinates of first order with respect to styrene concentration

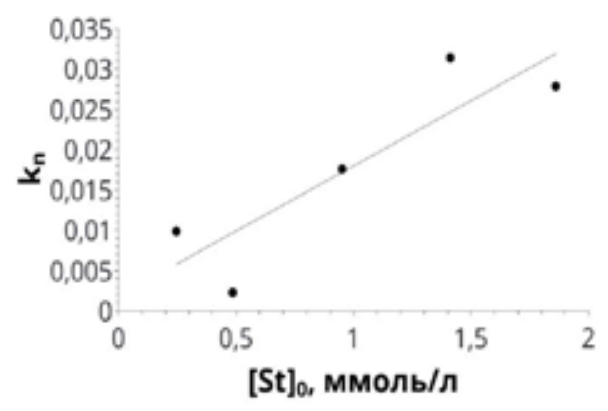

Рис. 4. Зависимость наблюдаемых констант скорости сополимеризации эмульсий от начальной концентрации стирола

Fig. 4. The dependencies of rate constants of the emulsion copolymerization on the styrene initial concentration

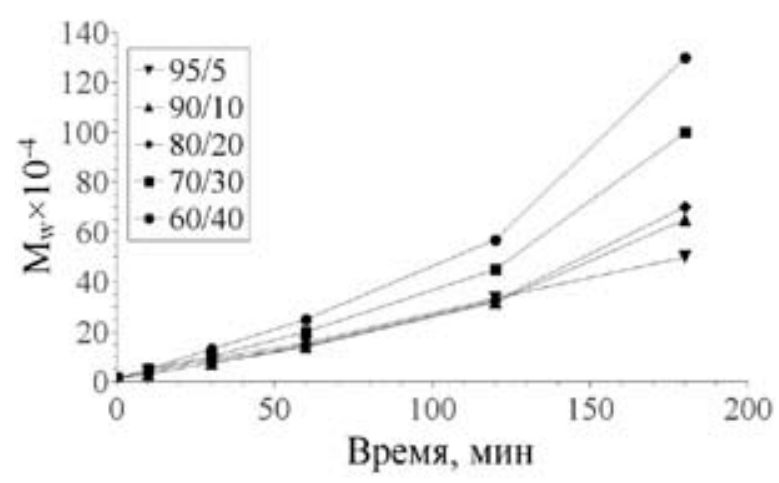

Рис. 5. Динамика средневесовой молекулярной массы сополимеров в процессе сополимеризации

Fig. 5. Dinamics of weight average molecular weight of the copolymers in the copolymerization process

Таблица 2. Физико-механические характеристики блок-сополимеров ПАЛ-полистирол

Table 2. Physical and mechanical characteristics of the block copolymers polyangelicalactone-polystyrene

\begin{tabular}{|c|c|c|c|c|}
\hline Стирол, мас. $\%$ & $\mathrm{M}_{\mathrm{W},} \times 10^{4}$ & $\sigma_{\mathrm{p}}, \mathrm{M \Pi a}( \pm 4)$ & $\varepsilon, \%( \pm 7 \%)$ & $\sigma_{\mathrm{t}}, \mathrm{M \Pi а}( \pm 4)$ \\
\hline 5 & 50 & 28 & 120 & 20 \\
\hline 10 & 65 & 29 & 120 & 21 \\
\hline 20 & 70 & 32 & 100 & 28 \\
\hline 30 & 100 & 35 & 60 & 30 \\
\hline 40 & 130 & 38 & 24 & - \\
\hline $\begin{array}{c}\text { Полистирол, } \\
\text { ГОСТ 28250-89 }\end{array}$ & & $22,5-24,5$ & $\geq 35$ & 25 \\
\hline
\end{tabular}

$\sigma_{\mathrm{p}}$ - разрушающее напряжение, $\sigma_{\mathrm{T}}-$ предел текучести, $\varepsilon$ - относительное удлинение. 
Таблица 3. Потеря массы отвержденных сополимеров полистирол-полиангеликалактон в процессе биодеградации образцов в серой лесной почве и в компосте

Table 3. Weight loss of the solidified copolymers polyangelicalactone-polystyrene during its biodegradation in a grey forest soil and compost

\begin{tabular}{|c|c|c|c|c|}
\hline \multirow{2}{*}{ Стирол, мас. \% } & \multicolumn{3}{|c|}{ Потеря массы сополимеров в ходе биодеградации, \% } \\
\cline { 2 - 5 } & \multicolumn{2}{|c|}{ Почва } & \multicolumn{2}{c|}{ Компост } \\
\cline { 2 - 5 } & 8 недель & 20 недель $/ 2,5$ & 8 недель & 20 недель \\
\hline 5 & 14,3 & $36,4 / 2,54$ & 20,4 & 91,3 \\
\hline 10 & 11,4 & $28,2 / 2,47$ & 19,9 & 87,3 \\
\hline 20 & 9,6 & $19,2 / 2,0$ & 15,7 & 85,5 \\
\hline 30 & 9,2 & $17,6 / 1,91$ & 13,6 & 82,4 \\
\hline 40 & 8,0 & $17,1 / 2,13$ & 11,2 & 80,5 \\
\hline
\end{tabular}

длительных временах выдерживания фрагментация и разрушение образцов. Потеря массы полимеров в почве составляет 17-36 \% за 20 недель, биодеградация в компосте протекает значительно глубже и быстрее, до 80-90 масс. \%.

Потеря массы образцов при деградации в почве пропорциональна продолжительности процесса (образцы с содержанием стирола 5 и 10 \%) или замедляется со временем (образцы с содержанием стирола 20-40 \%). Биодеградация в компосте, наоборот, ускоряется во времени в 3-5 раз в период 8-20 недель (табл. 3).

В трех случаях деградации полимеров с содержанием стирола 20-40 мас. \% в компосте потеря массы сополимеров превышает содержание ПАЛ в них. Это означает, что в этих блоксополимерах биодеструкции подвергаются не только фрагменты полиангеликалактона, но и полистирол. Следовательно, можно предполагать, что при достаточной продолжительности биодеградации полистирольные блоки могут полностью разрушиться. Такие возможности разрушения устойчивых фрагментов сополимеров в присутствии легко биодеградируемых компонентов хорошо известны [9].

\section{Заключение}

Изучена кинетика эмульсионной радикальной сополимеризации полиангеликалактона и стирола, инициированная 4,4-азобис-4-цианпентановой кислотой. Процесс имеет первый порядок по концентрации стирола и протекает при 340 К в течение 3 ч. Отверждение полученных микрогелей трифторидом бора при 423 К дает блок-сополимеры разветвленной структуры с прочностными показателями, превосходящими требования ГОСТ 28250-89 к ударопрочному полистиролу. Молекулярная масса сополимеров возрастает в процессе полимеризации с 6-9 тыс. до 40-1200 тыс. и возрастает при увеличении доли стирола в сополимере. Полученные материалы поддаются биодеградации в серой лесной почве и при компостировании с растительными остатками. В последнем случае потеря массы в результате биодеградации в течение 20 недель превышает 80-90 \% в зависимости от состава блок-сополимера и превышает содержание полиангеликалактона в нем. Это означает, что биодеградации в полученных блоксополимерах поддаются фрагменты и полиангеликалактона, и полистирола.

$$
-267-
$$


Полученные сополимеры могут проходить стадию отверждения прессованием совместно с волокнистыми полимерами, например целлюлозой, и это открывает возможности создания новых биодеградируемых композиционных материалов.

«Исследование выполнено при частичной финансовой поддержке базового проекта № 0356-2016-0505 (V.46.4.2) Программы фундаментальных научных исследований государственных академий наук на 2013-2020 годы и при финансовой поддержке Российского фонда фундаментальных исследований, Правительства Красноярского края, Красноярского краевого фонда науки в рамках научного проекта № 18-43-240003 «Разработка научных основ технологии переработки природного органического сырья в биодеградируемые композиционные материалы на основе альфа-ангеликалактона и целлюлозы».

\section{Список литературы}

1. Тарабанько В.Е., Кайгородов К.Л., Соколенко В.А., Черняк М.Ю. Исследование полимеризации $\alpha$-ангеликалактона. Химия растительного сырья 2006. T. 2, С. 37-41. [Tarabanko V.E., Kaygorodov K.L., Sokolenko V.A. Chernyak M.Yu. Study of $\alpha$-angelicalactone polymerization. Chemistry of plant raw material 2006. Vol. 2, P. 37-41. (In Russ.)]

2. Chen, T., Qin, Z., Qi, Y., Deng, T., Ge, X., Wang, J., Hou, X. Degradable polymers from ring-opening polymerization of $\alpha$-angelica lactone, a five-membered unsaturated lactone. Polymer Chemistry 2011. Vol. 2(5), P. 1190-1194.

3. Kaygorodov K.L., Tarabanko V.E., Tarabanko N. Thermodynamics of $\alpha$-angelicalactone polymerization. Cogent Chemistry 2018, Vol. 4(1). https://doi.org/10.1080/23312009.2018.1443689

4. Tarabanko V.E., Kaygorodov K.L. New biodedradable polymers based on $\alpha$-angelicalactone. Chemistry for Sustainable Development 2010. Vol. 18(3), P. 321-328.

5. Tarabanko V.E., Kaygorodov K.L. New Environmentally Benign Polymers Produced by Copolymerization with $\alpha$-Angelicalactone. Macromolecular Symposia 2015. Vol. 354(1), P. 367-373.

6. Патент 2482134 РФ. Тарабанько В.Е., Кайгородов К.Л. Ильин А.А. Биодеградируемые полимеры на основе стирола и полиангеликалактона. Опубл. 20.05.2013. [Patent 2482134 RU. Tarabanko V.E., Kaygorodov K.L., Ilin A.A. Biodegradable copolymers based on styrene and polyangelicalactone. Publ. Date 20.05.2013 (In Russ.)]

7. Patent 5010179 US. Lai J.T. Process for the preparation of mixed, symmetrical azonitrile dicarboxylic dicyano acids and initiators. Publ. Date 23.04.1991.

8. Khosravi M.M., Andrus M.B., Burt S.R., Woodfield B.F. Generalized preparation method and characterization of aluminum isopropoxide, aluminum phenoxide, and aluminum n-hexyloxide. Polyhedron 2013. Vol. 62, P. 18-25.

9. Nikolic V., Velickovic S., Popovic A. Biodegradation of polystyrene-graft-starch copolymers in three different types of soil. Environmental Science and Pollution Research 2014. Vol. 21(16), P. $9877-$ 9886. 